\title{
LAS CLASES MEDIAS TRADICIONALES Y LA DERECHA RADICAL EN FRANCIA: UNA EXPLICACIÓN CULTURAL Gabriel Goodliffe*
}

RESUMEN: Este ensayo desarrolla una explicación de clase y cultura sobre el persistente resurgimiento de la derecha radical en Francia. Su principal afirmación es que la derecha radical es mejor entendida como una tradición política continua cuyo apelativo puede ser rastreado en las modalidades y consecuencias de la modernización económica y política del país desde mediados del siglo XIX. Se analizan los valores económicos y políticos específicos propios de los miembros de esta categoría social para ayudar a explicar su prolongada atracción hacia el excluyente y autoritario discurso y programas de la derecha radical francesa.

$$
\text { rode }
$$

The Traditional Middle Classes AND

THE RADICAL RIGHT IN FRANCE: A CULTURAL EXPLANATION

ABSTRACT: This paper develops a class-cultural explanation for the persistent resurgence of the Radical Right in France. Its principal claim is that the Radical Right is best understood as a continuous political tradition whose appeal can be traced to the modalities and consequences of the country's economic and political modernization since the mid nineteenth century. The paper analyzes the specific economic and political values which members of this social category evolved in order to help explain their longstanding attraction to the exclusionary and authoritarian discourse and program of the French Radical Right.

PALABRAS CLAVE: modernización, oficio, pequeños independientes.

KEY WORDS: modernization, métier, small independents.

* Departamento Académico de Estudios Internacionales, ITAM. 
Se prohíbe su reproducción total o parcial por cualquier medio, incluido electrónico, sin permiso previo y por escrito de los editores.

RECEPCIÓN: 20 de febrero de 2018.

APROBACIÓN: 14 de agosto de 2018.

DoI: $10.5347 / 01856383.0128 .000292930$

Estudios 128, pp. 15-53, vol. XVII, primavera 2019. 


\section{LAS CLASES MEDIAS TRADICIONALES Y LA DERECHA RADICAL EN FRANCIA: UNA EXPLICACIÓN CULTURAL*}

Una clase está al tanto de su identidad como un todo, se sublima a sí misma en cuanto tal, tiene su propia vida peculiar y su "espíritu" característico [...] Los miembros de una clase se comportan uno para con el otro en un modo característicamente diferente respecto de su conducta para con miembros de otras clases. Están en una asociación recíproca más cercana; se entienden mutuamente mejor; trabajan más fácilmente en colaboración; cierran filas y erigen barreras en contra del exterior; miran hacia el mismo segmento del mundo, con los mismos ojos, desde el mismo punto de vista, en la misma dirección.

Joseph Schumpeter, Imperialismo y clases sociales $^{1}$

El oficio supone no solamente cierta técnica de producción y de racionalidad económica, sino todo un conjunto de actitudes, perspectivas, sensibilidades y mentalidades, ligadas de fondo en el lugar que ocupan dentro del proceso de producción y en su interacción social común en su seno o en función de este [...] El oficio tiene una historia y tradiciones, a la vez objetivadas en herramientas, instrumentos, producciones, libros e instituciones incorporadas a los individuos cuyos gestos, actitudes, argot,

* Traducción de Aldo Guarneros Monterrubio.

${ }^{1}$ Joseph Schumpeter, Imperialism and social classes, 1951, Nueva York, A. M. Kelly, trad. H. Norden, pp. 107, 110. 
indumentaria, gesticulaciones y estilo de relacionarse son tanto más reconocibles por cuanto el oficio es más antiguo, su historia más rica, su calificación intrínseca más alta y su aprendizaje más difícil...

Bernard Zarca, El artesanado francés ${ }^{2}$

En este ensayo se desarrolla una explicación cultural de clase para el resurgimiento persistente de la derecha radical en Francia. La afirmación principal es que la derecha radical se comprende mejor en tanto que tradición política ininterrumpida, cuyo atractivo puede ser rastreado hasta las modalidades y consecuencias de la modernización económica y política del país desde mediados del siglo XIX. ${ }^{3}$ Esta generó una estructura social peculiar y modos específicos de sociabilidad y organización política que, a su vez, crearon condiciones culturales favorables a esta tradición derechista radical. Específicamente, como resultado de su evolución económica y sociopolítica, ciertos grupos de la sociedad francesa desarrollaron culturas políticas antimodernas e intransigentes que facilitaron su identificación con la derecha radical. ${ }^{4}$

${ }^{2}$ Bernard Zarca, L'artisanat français: Du métier traditionnel au groupe social, 1986, París, Economica, pp. 16-17.

${ }^{3}$ Entre los analistas de la derecha radical contemporánea, Mudde en particular ha subrayado lo apropiado del análisis político cultural con el fin de explicar el resurgimiento de partidos derechistas radicales en algunos países europeos, a la vez que da cuenta de su ausencia en otros. Curiosamente, no obstante, presenta la cultura política como una variable de oferta política, aunque parece más apropiado verlo como un factor de demanda política, puesto que - como Mudde mismo indica - afecta la receptividad de la gente al discurso y las ideas de la derecha radical. Véase Cas Mudde, Populist radical right parties in Europe, 2007, Cambridge, Cambridge University Press, pp. 248-253 y 297-303.

${ }^{4}$ La autonomía y la resistencia —o la "adhesividad"— de orientaciones culturales más allá de las condiciones socioestructurales que inicialmente les dio origen explica cómo las formas políticas tradicionalistas y antimodernas sobreviven en sociedades que aparentemente presentan las condiciones estructurales e institucionales para su desaparición. Véase Harry Eckstein, “A cultural theory of political change", American Political Science Review, 82/3 (1988), pp. 789-804; y Ewa Morawska y Willfried Spohn, “'Cultural pluralism' in historical sociology: Recent theoretical directions”, en Diana Crane (comp.), The sociology of culture, 1994, Cambridge, Blackwell, pp. 45-90. 
Históricamente, estos grupos constituyeron un amplio sector tradicional compuesto por pequeños comerciantes, artesanos y dueños de negocios, un segmento conocido en Francia como los petits indépendants (pequeños independientes). Últimamente, esta base de apoyo se ha ensanchado para incluir el creciente número de obreros industriales franceses, en particular los no calificados.

Estos grupos se distinguen por su susceptibilidad - histórica, en el caso de los petits indépendants, contemporánea, en el caso de obreros industriales - a la crisis social. Gracias a su apoyo, la derecha radical alcanzó su apogeo durante los periodos más intensos de dislocación económica y política experimentados por el país a lo largo del pasado siglo y cuarto. En una primera etapa, tales crisis fueron de naturaleza estructural, resultado de fuertes deterioros económicos tras rápidos cambios tecnológicos y sociales que impactaron desproporcionadamente a estos grupos. Por tanto, la primera gran ola de concentración comercial e industrial, durante las décadas de 1860 y 1870, y la revolución en la producción y en el consumo a la que dio pie, significó que los comerciantes y artesanos tradicionales sufrieron lo más duro de la depresión de las décadas de 1880 y 1890 . Asimismo, la rápida consolidación industrial ocasionada por la Primera Guerra Mundial y proseguida en el decenio de 1920 aseguró que los petits indépendants fuesen particularmente golpeados por la Gran Depresión. Este impacto empeoró por el miedo de los petits indépendants a la revolución tras la victoria del Frente Popular y la subsecuente ola de huelgas y ocupaciones de fábricas en el verano de 1936. Una dinámica similar caracterizó a la posguerra, cuando el país padeció su más profunda transformación económica y social desde el Segundo Imperio, sucedida por un periodo de prolongada crisis socioeconómica. Los petits indépendants $\mathrm{y}$, cada vez más, los obreros industriales fueron los más lastimados por esta crisis, avivada por el desempleo constantemente alto que se apoderó del país desde los primeros años de la década de 1980.

Sin embargo, las crisis sociales que causaron el resurgimiento de la derecha radical no se limitaron a los factores económicos puramente estructurales que afectaban el bienestar material y el estatus social de ciertas circunscripciones dentro de la sociedad francesa. Tales crisis 
también reflejaban las amenazas "subjetivas" percibidas por los miembros de estas circunscripciones, así como los factores o procesos socio estructurales "objetivos". Desde este punto de vista, el ascenso de la derecha radical fue un síntoma tanto de las preocupaciones del pueblo por un futuro incierto como de su condición real de privación material. A menudo, los petits indépendants y otros grupos de apoyo para la derecha radical no representaron los segmentos más pobres de la sociedad francesa. Provenían principalmente de las filas de la clase obrera industrial, así como de los desempleados, y prestaron su apoyo hasta hace poco a la extrema izquierda, más que a la derecha radical. Tal como Erwan Lecœur observó en su estudio reciente sobre el Frente Nacional, "básicamente, aquellos que votan por la [derecha radical] no son aquellos que no tienen nada, sino más bien aquellos que temen perder algo [...] y buscan resucitar, mediante este acto, una sensación desaparecida de autoestima". ${ }^{5}$ En este sentido, uno debe ser cuidadoso al hacer el balance de los componentes culturales, incluso psicológicos, que se inscriben dentro del fenómeno de la crisis, particularmente dado que se reflejan en una pérdida de "significado" o "identidad" subjetivamente sentida, aunque socialmente generalizada. ${ }^{6}$

A su vez, esta concepción "subjetiva" de la crisis sitúa la carga analítica en comprender las perspectivas culturales o cosmovisiones de los petits indépendants y de los obreros industriales que han sufrido crisis de identidad en la sociedad francesa moderna. Específicamente, ilustraremos cómo las respectivas experiencias de estos grupos ante la modernización económica y social los volvió particularmente susceptibles

${ }^{5}$ Erwan Lecœur, Un néo-populisme à la française: trente ans de Front National, 2003, París, La Découverte, p. 238.

${ }^{6}$ Esta concepción subjetiva de la crisis implica una dislocación general de las perspectivas del individuo en torno al mundo y un cuestionamiento fundamental de su lugar y su significado en él. Semejante concepción es particularmente útil para explicar cómo, en tanto que función de sus identidades y perspectivas sociales culturalmente definidas, los miembros de grupos sociales "antimodernos" llegan a concebir y a reaccionar ante su papel económico cada vez más insostenible y su posición social marginal en la avanzada sociedad capitalista. Cfr. Alain Bihr, Le spectre de l'extrême droite: Les français dans le miroir du Front National, 1998, París, Éditions de L'Atelier; L'actualité d'un archaïsme: La pensée d'extrême droite et la crise de la modernité, 1998, Lausana, Page Deux, y, en forma condensada, "Crise du sens et tentation totalitaire", en Le monde diplomatique, mayo 1992, pp. 16-17. Para una formulación similar de la crisis sociocultural, véase también E. Lecœur, op cit., cap. 8, y Michel Wieviorka, "Bases du national-populisme", Le débat, 61 (1990), p. 37. 
a tales crisis e hizo de ellos clientelas políticas adecuadas para la derecha radical. Por una parte, sus miembros adoptaron normas y valores que reflejaban su función y posición de clase dentro de la economía y la sociedad francesas. Debido al papel central que ocuparon en una economía basada, hasta bien avanzado su desarrollo, en la producción y el comercio menores, los petits indépendants franceses desarrollaron un sistema cultural de clase distinto, arraigado en el "trabajo" de propiedad económica de pequeña escala, en los valores de la destreza y en la implicación de la familia en el manejo de sus empresas. Este modelo de producción engendró una moralidad tradicionalista y patriarcal entre estos estratos, basada en el respeto a la propiedad y a la autoridad privadas, y en los valores del trabajo duro, la frugalidad y la abnegación. Como veremos, esta moralidad suscitó sentimientos de frustración y resentimiento entre los petits indépendants que fueron aprovechados hábilmente por la derecha radical. Asimismo, ello se tradujo en una disposición económicamente conservadora que dispuso a los petits indépendants tanto en contra de las formas de capitalismo "avanzadas" y racionalizadas como en contra del socialismo dirigido por el Estado o la democracia social intervencionista. En el caso de los obreros industriales, el carácter oneroso del trabajo fabril y las condiciones colectivas en las que se realizaba se volvieron indicadores poderosos de identificación social. Los obreros franceses afianzaron una identidad de clase opositora, que giraba en torno a la lucha para superar sus condiciones laborales y mejorar su posición en la sociedad capitalista. Sin embargo, una vez que erosionaron las estructuras económicas y sociales subyacentes a esta identidad de clase colectiva, también ellos se volvieron cada vez más receptivos de las prescripciones de la derecha radical.

Por otra parte, las cosmovisiones culturales de estos grupos se modelaron según sus respectivas experiencias sociopolíticas dentro de la moderna sociedad francesa, específicamente por su relación cada vez más tensa con el Estado republicano. Su influencia, en declive, sobre las instancias representativas y administrativas de este último, particularmente en comparación con otras circunscripciones económica y políticamente ascendentes, alimentó su creciente desilusión para con la democracia republicana. Por tanto, cada uno de ellos pasó de representar el pilar 
principal del Estado republicano — petits indépendants durante la belle époque, obreros industriales durante las trente glorieuses (los gloriosos treintas) - a constituir fuentes significativas de oposición. Desde el punto de vista de los petits indépendants franceses, el Estado republicano abandonó progresivamente o incluso traicionó el ideal de la democracia de pequeños productores que sustentó su cosmovisión sociopolítica. A su vez, dado que presidió durante la modernización económica y social del país, llegaron a culparlo por su progresiva marginación política y declive socioeconómico. Incluso antes de la derrota de 1940, que disuadió a las élites gobernantes de adoptar un programa exhaustivo de modernización, muchos petits indépendants perdieron la confianza en la capacidad del Estado francés para proteger sus intereses. Y a medida que el estigma de posguerra de Vichy y de la ocupación se desvanecía, se apegaron cada vez más a las garantías políticas de la pequeña producción ofrecidas por la derecha radical.

En tiempos recientes, este rechazo al Estado republicano se ha extendido al creciente número de obreros industriales que se han vuelto prescindibles por la transformación estructural de la economía francesa desde principios de la década de 1980. En particular, esta transformación ha tenido un impacto catastrófico sobre las organizaciones políticas y sectoriales, notablemente sobre el partido comunista y los sindicatos, que de 1930 en adelante vincularon a la clase obrera francesa con el orden republicano. Despojados de estos agentes de identificación y participación republicanas, los obreros industriales se volvieron una circunscripción política cada vez más apática y "disponible”. Por lo tanto, al igual que los petits indépendants anteriores a ellos, muchos se fijaron en el mensaje excluyente y xenófobo de la derecha radical.

En suma, la derecha radical aprovechó sucesivamente las frustraciones, preocupaciones y resentimientos de los petits indépendants y de los obreros industriales, que estaban cada vez peor equipados funcional y culturalmente para vencer las dislocaciones económicas y sociales a las que se confrontaron en una sociedad francesa modernizadora. La concepción excluyente de pertenencia nacional, la perspectiva misoneísta y el discurso afirmante de orden sirvieron para asegurarles su vigencia y valor sociales. La derecha radical, al ofrecer una visión alternativa a un 
presente angustiante y a un futuro premonitorio, un poderoso fundamento excluyente de identidad y chivos expiatorios prestos para culpar por su declive, restableció un sentido de propósito colectivo a estas circunscripciones asediadas estructural y culturalmente. De este modo, representó una aportación política que se articuló con las demandas políticas generadas por tales crisis estructurales y culturales.

En las páginas que siguen esbozamos los sistemas socioculturales y politicoculturales que indispusieron a las clases medias tradicionales francesas contra la modernización y la modernidad capitalista y, como consecuencia, las inclinó a la derecha radical. Aunque se extendería más allá del ámbito de nuestra tarea inmediata, podría realizarse un estudio semejante en relación con los obreros industriales franceses, los cuales, en vísperas del siglo XXI, se mostraban igualmente reacios al avance del capitalismo globalizado posindustrial, con consecuencias políticas cada vez más parecidas. Por tanto, en lo siguiente pueden rastrearse en forma, si no en contenido, los rasgos generales para ese estudio, en caso de que quiera intentarse.

\section{La anatomía cultural de la indépendance}

No ascender muy alto, quizá, pero por uno mismo

CYRANO DE BERGERAC ${ }^{7}$

Yo voy a decirle: lo que le hace falta a los franceses, ;es un nuevo Hitler!

UN QUESERO PARISINO EN $1978^{8}$

En el fondo, la supervivencia de un sector sustancial de los petits indépendants en Francia puede ser visto como la expresión socioestructural del deseo atávico del individuo de autonomía económica y social. Ello

${ }^{7}$ Edmond Rostand, Cyrano de Bergerac, 1983, París, Gallimard, p. 142.

${ }^{8}$ Citado en Nonna Mayer, "Les classes moyennes indépendantes dans la vie politique: le cas des petits commerçants français”, tesis doctoral, 1984, Institut d'Études Politiques de Paris, p. 455. 
implica la simultánea propiedad y "trabajo" de la propiedad productiva en pequeña escala por el individuo y su familia. De acuerdo con esta concepción minimalista de la producción y la organización económicas, el dueño de la pequeña empresa recurre a la mano de obra externa solo como último recurso, en tanto extensión de su propia labor. Como lo indica un autor, el petit indépendant"es en primer lugar y principalmente un obrero [...] que es al mismo tiempo parte de la clase propietaria". 9

Los petits indépendants, así, representan una forma intermedia de producción que se plasma en su posición y estatus ambiguos dentro del capitalismo industrial. Por una parte, podrían no ser tomados en cuenta como proletariado, al ser propietarios de sus propios instrumentos de producción; por la otra, no pueden ser definidos como burgueses a causa del carácter personal de la labor — a menudo manual — por la cual ellos "trabajan" su pequeña propiedad, ganando frecuentemente un ingreso semejante al salario de un obrero industrial. En Das Kapital, Karl Marx identifica esta ambigüedad fundamental en el fondo de la identidad funcional y social de los petits indépendants:

El campesino o artesano independiente se separa en dos personas. En tanto que dueño de los medios de producción, es un capitalista; en cuanto trabajador, es su propio asalariado. En tanto capitalista, por tanto, se paga a sí mismo su sueldo y cobra sus ganancias sobre su capital; esto es, se explota a sí mismo como trabajador asalariado y se paga a sí mismo, en la plusvalía, el tributo que el trabajo debe al capital. ${ }^{10}$

Su posición ambigua dentro de la economía capitalista refleja el estatus peculiar de los petits indépendants como vestigios funcionales de una era pasada. Conservan modos de producción asociados con una industria artesanal precapitalista, por una parte, y una agricultura campesina de pequeña escala, por otra. Aludiendo a la persistencia de estos

${ }^{9}$ François Gresle, "L'indépendance professionnelle: Actualité et portée du concept dans le cas français", Revue française de sociologie, 22 (1981), pp. 488-489.

${ }^{10}$ Karl Marx, "Productivity of capital. Productive and unproductive labor", en Capital, vol. IV: Theories of surplus value, parte I, 1969, Londres, Lawrence and Wishart, p. 408. 
modos anticuados de producción dentro de la sociedad capitalista industrial, Marx escribe:

En la producción capitalista siempre hay ciertas partes del proceso productivo que son llevadas a cabo en la forma característica de modos anteriores de producción en que las relaciones de capital y trabajo asalariado todavía no existían y en la que, consecuentemente, los conceptos capitalistas de trabajo productivo e improductivo son totalmente inaplicables. ${ }^{11}$

La ambigüedad funcional de los petits indépendants dentro del capitalismo industrial, que refleja las relaciones económicas y sociales enraizadas en un pasado precapitalista, engendraron una mezcla peculiar de perspectivas, actitudes y valores o cultura "de clase" entre ellos. Considerado como un todo, estos rasgos constituyen el sistema cultural - o, según la frase de E. P. Thompson, la "economía moral”- de la indépendance, que sustenta la cosmovisión de estos estratos en Francia. ${ }^{12}$ Este sistema cultural se transmitió por medio de los sobrevivientes de un significativo sector artesanal y comerciante, al lado de la industria y el comercio "modernos", y tuvo implicaciones importantes no solo para el desarrollo económico del país, sino también para su evolución social y política.

Tres correlatos culturales principales de la indépendance definen la identidad económica y social de los petits indépendants franceses: el ideal de autonomía económica y social, el espíritu de oficio o métier y la primacía de la familia. Estos elementos sostienen las relaciones eco-

${ }^{11}$ Karl Marx, "Appendix: Results of the immediate process of production”, en Capital: a critique of political economy, vol. I, 1981, Nueva York, Penguin Books, trad. de B. Fowkes, p. 1042.

${ }^{12}$ Citado en Frank Bechhofer y Brian Elliott, "Petty property: The survival of a moral economy", en F. Bechhofer y B. Elliott (comps.), The petite bourgeoisie, 1981, Londres, Macmillan, pp. 182-200. En palabras de François Gresle, la noción de indépendance surge como el "principio psico-sociológico unificador", de acuerdo con el cual pequeños productores y comerciantes son capaces de constituirse a sí mismos como "una clase social [...] la piedra angular de una filosofía social profundamente anclada en el inconsciente colectivo de comerciantes [y] artesanos". F. Gresle, "Indépendants et petits patrons", tesis doctoral, 1978, Université René Descartes, p. 217 y 242 . 
nómicas y sociales de los petits indépendants, condicionan su cosmovisión e informan su comportamiento social y político. El primero de estos motivos, el ideal de autonomía económica y social, está arraigado en el individualismo agrario precapitalista característico del campesinado francés. Al implicar la propiedad de los medios de producción y el abastecimiento mediante el trabajo propio de la productividad que se le asocia, tal individualismo de pequeño productor plasma un deseo básico de "ser uno mismo su propio jefe" y el consecuente rechazo del empleo asalariado. Tal como vio Nonna Mayer en sus entrevistas a comerciantes parisinos, los petits indépendants retrocedieron uniformemente ante la reglamentación del trabajo de oficina y de fábrica, caracterizado por uno de sus interlocutores como "esclavitud pagada". Describieron la condición de la clase obrera, en particular, como sinónimo de la subyugación económica y social. ${ }^{13}$

En cambio, los petits indépendants persiguen ocupaciones que dan rienda suelta a su iniciativa individual. Los artesanos y pequeños comerciantes conciben "su empresa como su creación, que realizaron de acuerdo con su idea y en la que invirtieron parte de sí mismos". ${ }^{14}$ Para ellos, el autoempleo representa el camino a un estatus social más alto, un vehículo para escapar de apuros económicos y de la inferioridad social asociada con el trabajo asalariado. ${ }^{15}$ A la vez, su concepción de libertad económica, muy identificada con la pequeña propiedad de negocios,

${ }^{13}$ N. Mayer, op. cit., p. 272.

${ }^{14}$ Ibid., p. 273.

${ }^{15}$ Esta noción fue claramente articulada por Gérard Nicoud, líder del CID-UNATI, la principal formación sectorial abogando en nombre de los petits indépendants a finales de la década de 1960 y comienzos de la siguiente. En Les dernières libertés, menottes aux mains, un tratado en el cual argumenta a favor de la preservación de los pequeños gremios artesanales y comerciales, afirma que "los pequeños comerciantes y artesanos, miembros de las profesiones independientes, NO DEBEN desaparecer. Primero, porque representamos ese contacto humano tan necesario para el 'cliente', y eso no existe en aquellas grandes estructuras [comerciales] anónimas; segundo, porque tenemos un conocimiento íntimo de nuestro gremio del cual el empleado efímero, no especializado, carece tanto, el cual, no obstante, permanece esencial [...] Pero, especialmente, porque representamos la posibilidad de AVANCE, el potencial que todo hombre ha de sentir de volverse algún día su propio dueño, con todas las oportunidades que esto implica, pero también con la satisfacción de ser capaz de dar total rienda suelta a la iniciativa propia, a la inteligencia propia, al trabajo propio [...] Un jornalero, un empleado, un asalariado deben, si están dispuestos, tener la posibilidad y los medios para probar su suerte, para tener un día su propia empresa, que los emancipará y les permitirá realizar completamente todas sus facultades intelectuales y manuales $[\ldots]$ 
se amplió hasta ser una visión social integral. Imaginaron la sociedad basada en pequeños negocios individuales como esencialmente libre, suelta y favorable a la creatividad y el potencial individuales. ${ }^{16}$

El correlato estructural del ideal de la indépendance es el compromiso con la pequeñez. Proveniente de su limitada capacidad financiera para emprender nada excepto las más rudimentarias empresas, este compromiso también refleja el deseo de los petits indépendants de salvaguardar su autonomía económica y el distintivo estatus social que derivan de él. Prefieren seguir siendo pequeños e independientes a expandir sus ganancias a costa de renunciar al control de sus empresas. ${ }^{17}$ Quizá como una racionalización ex post facto de la marginalidad económica de sus empresas, comerciantes y artesanos parecen dar mayor importancia a preservar su estatus independiente socioeconómico que a obtener un ingreso mayor, particularmente si este implica formar en

[Por tanto,] una vez que nuestra clase social desaparezca, el trabajador, el empleado, el asalariado nunca será capaz de aspirar a este avance [social]. En particular, con su desaparición, será la libertad misma lo que desaparecerá, porque aun cuando nos cueste caro de momento, ya sea financieramente, ya en términos del trabajo dedicado, es el amor que mostramos por esta libertad, el amor por la independencia, lo que ha conducido a tantos de nosotros a dejar detrás la oficina o la fábrica con el fin de establecer negocios por nuestra cuenta. Es este amor por la libertad lo que hoy empuja a pelear con el fin de salvarla, porque nosotros somos, cuando todo está dicho y hecho, los "últimos guardianes de las libertades individuales"'. Citado en Christian Baudelot, Roger Establet y Jacques Malemort, La petite bourgeoisie en France, 1974, París, Maspero, p. 272.

${ }^{16} \mathrm{La}$ autonomía profesional buscada por los petits indépendants correspondió a un deseo profundamente arraigado por la respetabilidad y el estatus social que fue postulado con mayor frecuencia a diferencia de la condición proletaria. En este contexto, la reivindicación y defensa de la libertad individual fue tanto una legitimación normativa de este deseo por el avance social, como un medio por el cual el petit indépendant podría expresar su superioridad normativa al asalariado, a pesar del gradual deterioro de su posición socioeconómica en relación con este último. A su vez, en razón de la superioridad normativa y social que ello implicó en relación con el trabajo asalariado, el estatus de indépendance llegó a ser considerado por pequeños artesanos y comerciantes como un fin en sí mismo, garantía de una merecida identidad y existencia sociales. En cuanto tal, representó la consumación de una trayectoria social ascendente que se salvaguarda celosamente al conquistarla y a la que se aferra incluso con mayor fiereza ante la siempre creciente volatilidad económica e inestabilidad social. Gresle, Indépendants et petits patrons, p. $63 \mathrm{y}$ Mayer, op. cit., p. 274.

${ }^{17}$ De ahí su recelo, evidenciado históricamente por los petits patrons ("pequeños jefes"), a recurrir a capital externo con el fin de incrementar el tamaño de sus empresas y su temor a que semejante crecimiento los sometiese a un régimen regulativo y fiscal inaceptablemente oneroso. Ibid., pp. 484 y 950. 
las filas de los asalariados. A final de cuentas, están contentos con sus empresas pequeñas, porque tal es el precio de que las gestionen ellos mismos. Privilegiando la autonomía sobre la riqueza y el control sobre el crecimiento, la consigna que resume la actitud de los artesanos y pequeños comerciantes sigue siendo tenazmente ça me suffit ("eso me basta"). ${ }^{18}$

El segundo componente cultural del sistema de la indépendance es el fuerte apego de los petits indépendants a su oficio (métier). En la medida en que este "espíritu del oficio", para hacer uso de la expresión de Bernard Zarca, da forma concreta y contenido específico a su función económica, constituye un elemento primordial en la identidad social de los comerciantes y artesanos. ${ }^{19}$ Históricamente rastreable hasta los gremios corporativos — las chambres des métiers ("cámaras de oficios") que controlaron el acceso a los oficios desde el Medievo tardío hasta la Revolución Francesa, la noción de métier implica el dominio de la habilidad productiva y del saber hacer técnico subyacente a la profesión del pequeño productor o negociante. Revestido de identificaciones y resonancias culturales compartidas, este apego al métier subtiende la común perspectiva cultural, distinguiendo a comerciantes y artesanos como un grupo o clase dentro de la sociedad francesa. ${ }^{20}$

La naturaleza del trabajo autoempleado o "independiente", que presenta atributos que subyacen a una común experiencia y concepción

${ }^{18}$ Mayer, op. cit., p. 365.

${ }^{19}$ Zarca, op. cit., p. 20.

${ }^{20}$ Evidentemente, este apego general al métier tuvo en cuenta la variación considerable en la definición de las identidades económicas y sociales de los pequeños negociantes y productores. Las dimensiones prácticas y técnicas de varios gremios, la naturaleza específica del trabajo que ordenaban y los materiales que utilizaban, reflejaban una amplia serie de relaciones productivas que sustentaban los papeles económicos de los petits indépendants y los llevaba a desarrollar identidades sociales diferenciadas y matizadas entre ellos. A pesar de su adherencia común a un métier, los petits indépendants eran diversos, de tal suerte que sería excesivamente reduccionista imaginar que eran cultural o sociopolíticamente homogéneos de la misma manera en que, por ejemplo, podría decirse que los obreros industriales no calificados son culturalmente homogéneos. En cambio, sería más apropiado decir que, en virtud de su ejercicio universal de un oficio particular, los petits indépendants desarrollaron una sensibilidad común y ciertas disposiciones y perspectivas compartidas que crearon una mentalidad general o "forma de pensar" entre ellos. Acerca de las diferencias internas manifiestas dentro del artisanat ("artesanado") en particular y del sector independiente en general, véase ibid., pp. 234-235. 
del trabajo, une funcionalmente a los petits indépendants y facilita su desarrollo de una perspectiva y una psicología cultural común. Esto último revela una aproximación totalista al trabajo, en lugar de una especializada, de modo que el artesano, en señalado contraste con el obrero industrial, participa en todas las etapas de concepción, producción y venta de un bien o un servicio particular. Además, los petits indépendants desarrollaron un sentido diferente del tiempo, al dedicarse a su obra hasta que estuviera terminada, y no según un número de horas fijado de antemano, sin distinción del rendimiento. ${ }^{21}$ En suma, los atributos y las restricciones estructurales y temporales del métier inculcan ciertas disposiciones actitudinales y conductuales entre los petits indépendants que asientan en conjunto las bases para una distinta mentalidad o "cultura" socioeconómica. Las necesidades del métier presuponen, tal como Bernard Zarca lo indica, "la reproducción de una división del trabajo tanto técnica como social" que esté "subordinada a la adherencia [...] a valores específicos, lo que constituye una cultura verdadera que produce normas de comportamiento". ${ }^{22}$

El tercer componente de la indépendance es la primacía concedida a la familia en tanto que lugar de la existencia económica y social de

${ }^{21} \mathrm{Al}$ escribir acerca de la temporalidad del trabajo agricultor que, como vimos, es bastante semejante al de los artesanos e incluso al de los comerciantes, Monique Vincienne ha aducido que, en el contexto del trabajo independiente, "el tiempo no tiene valor en y de sí mismo; lo que cuenta son sus contenidos en obra y en producción, lo cual es la razón de que al menos el producto del trabajo es aproximadamente medido, pero no la duración del trabajo". Monique Vincienne, Du village à la ville. Le système de mobilité des agriculteurs, 1972, París, Mouton, pp. 53-54.

${ }^{22}$ B. Zarca, op. cit., p. 19. En este sentido, la evolución orgánica de los gremios, a lo largo de los siglos, sirvió para forjar y endurecer progresivamente las distintas orientaciones socio-culturales de los petits indépendants, fundamentándolos firmemente en la noción de métier. Esto fue particularmente verdadero en el caso del artisanat, en el que una fuerte cultura basada en el métier era transmitida inter-generacionalmente a través de las antiquísimas instituciones del apprentissage (aprendizaje) y del compagnonnage (de la capacitación). A su vez, esta prominencia cultural del métier fue a menudo tan importante precisamente al definir la identidad económica y social del comerciante. Tal como varios estudios han mostrado, esto se debió principalmente al hecho de que históricamente la función productiva o transformativa de la mayoría de los pequeños comerciantes, al preparar sus bienes para la venta, fue un componente tan significativo de su obra como la misma venta de aquellos bienes a su clientela. Acerca de este punto, véase Alain Faure, "L'épicerie parisienne au XIXe siècle ou la corporation éclatée", Le mouvement social, 108 (1979), pp. 115-117. 
los petits indépendants. Como vimos, el sector petit indépendant se caracterizó históricamente por una baja proporción de trabajo asalariado en relación con el trabajo familiar no remunerado. ${ }^{23}$ Esto reflejó la primacía de la ayuda familiar en la actividad y la supervivencia económica de los petits indépendants. A menudo, el trabajo familiar no remunerado fue la garantía funcional de la independencia socio-profesional, mientras que la institución del matrimonio representó "la condición necesaria, si no suficiente, para la existencia de un oficio". ${ }^{24} \mathrm{En}$ muchos casos, las obligaciones de la indépendance se extendieron a la familia entera, de modo que se reclutaban los hijos y la esposa para el funcionamiento diario de la tienda o del taller familiar. En estas condiciones, la familia nuclear se volvió el sustituto estructural - una reserva de trabajo que significaba la diferencia entre la solvencia y la bancarrota - de la pequeña empresa autónoma. Ello representa, entonces, un componente intrínseco y esencial de las relaciones de producción de los petits indépendants, la garantía práctica de su existencia económica y social. ${ }^{25}$

Por tanto, apenas sorprende que, de todas las categorías socio-profesionales que comprehende la sociedad francesa, los comerciantes y artesanos estén entre los más firmes defensores de los valores familiares tradicionales en la sociedad francesa. ${ }^{26}$ En efecto, los principios

${ }^{23}$ Mayer estima que en 1975, la ayuda familiar en el sector comercial comprendió 685100 personas, una proporción que cayó continuamente en la década de 1980 y sobre todo la siguiente, como expresión del declive general del número de los petits indépendants así como del incremento proporcional de la mano de obra asalariada femenina. En 1990, considerando el sector independiente no agricultor como un todo, la cifra disminuyó a 279000 (424 000, si uno incluye a los miembros asalariados de la familia) y en 2001 a 176000 (335000 con los miembros asalariados de la familia). Véase Mayer, op. cit., p. 90, y Nathalie Blanpain y Dominique Rouault, "Les indépendants et dirigeant dans les années quatre-vingt-dix", en Données sociales: la société française 2002-2003, 2002, París, INSEE, pp. 427-428.

${ }^{24}$ Gresle, Indépendants et petits patrons, pp. 291, 295-296 y 298.

${ }^{25} \mathrm{Al}$ escribir en 1926 acerca de las condiciones sociales del artisanat, el comentador social Jean Delage captó hábilmente este compromiso totalista de la familia en el funcionamiento de los pequeños negocios independientes: "El artesano trabaja en casa. Tiene su tienda, su casa. El matrimonio es, para él, la fundación de su gremio. Su esposa será su ayudante; sus hijos también. Cuantos más hijos, más asistentes y más prosperará su empresa". Citado en Steven Zdatny, The politics of survival: Artisans in twentieth-century France, 1990, Nueva York, Oxford University Press, p. 43.

${ }^{26}$ Véase Mayer, op. cit., p. 495. 
y las relaciones normativas de la autoridad, subyacentes a la familia nuclear tradicional, son idealmente apropiados para la operación de la pequeña empresa independiente. Las relaciones paternalistas que prevalecen en el lugar de trabajo artesanal pueden ser vistas como la extensión natural de las relaciones patriarcales imperantes en la familia tradicional. Así como el esposo manda en la familia, así el petit patron gobierna su empresa. A su vez, así como la operación y la solvencia del negocio dependen de las contribuciones de la familia, el estatus y el bienestar de la familia está inextricablemente vinculado al desempeño del negocio. La riqueza y el prestigio que se transfieren a la familia desde el negocio se vuelven la principal justificación de la existencia de este último. Como resultado, es cada vez más difícil distinguir la empresa de la familia como entidades económicas y sociales separadas. Los valores y las prerrogativas adscritas a la familia se imbrican efectivamente con los de la empresa, lo que refleja un sistema cultural unitario que abarca las dos esferas del trabajo y la vida privada. ${ }^{27}$

El sistema cultural de la indépendance, basado en la propiedad económica de pequeña escala y sostenido por los imperativos del métier y la defensa de la familia, se plasma en una moralidad peculiar que separa a los petits indépendants de otros grupos socio-profesionales. Esta moralidad "pequeñoburguesa" está constituida en torno a los tres valores interrelacionados del trabajo duro, la frugalidad y la abnegación, cada uno de los cuales cumple una función normativa vital en el manejo de la pequeña empresa independiente. Además de sostener la petite entreprise ("pequeña empresa"), el ethos del trabajo duro ratifica la primacía del métier que sustenta la identidad profesional y social de los

${ }^{27}$ Esta fusión de los asuntos de la familia con los de la empresa no fue específica solamente del grupo de los petits indépendants, aunque estos proveyeron el modelo primordial. Se extendió igualmente a empresas más grandes pertenecientes a familias - lo que David Landes ha llamado el modelo de la "empresa burguesa" francesa - y, por tanto, vino a caracterizar ciertos segmentos tradicionalistas de la gran burguesía francesa. Acerca de la propagación de este modelo cultural pequeño burgués a propietarios familiares empresariales mayores, véase en particular John Sawyer, "Strains in the social structure of modern France" y David Landes, "French business and the businessman", en Edward Mead Earle (comp.), Modern France: Problems of the third and the fourth Republics, 1951, Princeton, Princeton University Press, pp. 293-312 y 334-353. Para un análisis estadístico relativamente reciente del predominio de este modelo de empresa familiar entre empresas industriales y comerciales más grandes en Francia, véase Dean Savage, Founders, heirs and managers: French industrial leadership in transition, 1979, Beverly Hills, Sage publications. 
petits indépendants. A su vez, el valor de la frugalidad se vuelve el medio principal para preservar la viabilidad financiera y el estatus social de sus familias. Finalmente, estos imperativos gemelos se reúnen en una ética poderosa de abnegación que, como varios autores han señalado, yace en el corazón del sistema moral de los petits indépendants. Esta ética implica tanto sacrificar el ocio por el trabajo duro como renunciar al consumo por la frugalidad. Así, confiere un sentido de superioridad moral a los petits indépendants que la siguen, particularmente en comparación con el consumismo y la ostentación exhibida por sus — pretendidamente- superiores sociales.

Desde esta perspectiva, los principios del trabajo duro, frugalidad y abnegación que motivaron a los petits indépendants no son simplemente un reflejo de las necesidades funcionales y las limitaciones materiales que afrontan, sino que se proyectan como prueba de su superioridad moral ante, por una parte, un salariat ("asalariado") indolente y sin talento y, por otra, un grand patronat ("alto empresariado") indigno y decadente. ${ }^{28}$ Juntos, sirven como poderosas justificaciones normativas del papel y la posición de los petits indépendants dentro de la economía y la sociedad francesas. Al reforzar las instituciones de la pequeña propiedad económica, del métier y de la familia tradicional, el sistema moral rigorista legitima la función económica del sector petit indépendant y las relaciones sociales que lo caracterizan.

Al mismo tiempo, este exigente sistema moral, que les impide disfrutar los frutos de su trabajo y los somete a privaciones casi permanentes, se convirtió en una intensa fuente de resentimiento para los petits indépendants. ${ }^{29}$ Dirigido unas ocasiones contra los gros patrons ("grandes

${ }^{28}$ Pierre Bourdieu captó hábilmente el sentido de superioridad moral desarrollado por los petits indépendants como resultado de su ethos rigorista económico y social. Al describir una especie de "ética protestante" puesta al día, extrapolable a la petite bourgeoisie ("pequeña burguesía") de hoy, escribe: "En el contexto de intercambios sociales en que otros son capaces de mejorar garantías concretas, dinero, cultura o conexiones sociales, [la petite bourgeoisie] solo puede ofrecer garantías morales; (relativamente) pobre en capital cultural, económico y social, solo puede 'justificar sus pretensiones', como dicen, y de ese modo darse a sí misma la posibilidad de realizarlos en términos de pagar por ellos con sacrificio, privación y renuncia; en una palabra, de pagar por ellos con virtud". Véase Pierre Bourdieu, "Avenir de classe et causalité du probable", Revue française de sociologie, 15/1 (1974), p. 23.

${ }^{29}$ Mayer, op. cit., pp. 337-342. Véase también P. Bourdieu, "Condition de classe et position de classe", Archives européennes de sociologie, 7/1 (1966), pp. 201-223 y "Avenir de classe et causalité du probable", pp. 18-28. 
jefes") y otras contra los asalariados, los trabajadores ilegales, los desempleados "profesionales" y, cada vez más, los inmigrantes, este ánimo fue explotado por la derecha radical con efectos crecientes, mientras que la posición socioeconómica de los independientes se deterioraba progresivamente.

Este modelo cultural de la indépendance y la moralidad rigorista a la que da lugar constituyen importantes interfaces o "filtros" por los cuales los petits indépendants entienden los sucesos políticos y sociales. Abarcan ciertas actitudes fundamentales de los petits indépendants hacia la sociedad contemporánea la cual, a su vez, estructura sus perspectivas y creencias económicas y políticas. Este complejo de actitudes es capaz de deducirse del concepto de misoneísmo que, definido como el "odio por lo nuevo", implica una fuerte nostalgia por un orden socioeconómico pasado. ${ }^{30}$

Estas actitudes, que surgieron del conflicto entre el sistema cultural de la indépendance y los principios rectores de la sociedad industrial, equivalen a un repudio general de la modernidad socioeconómica, considerada por los petits indépendants tanto amenaza física como debilitamiento moral. Estos llegan a verse a sí mismos como los últimos defensores de los valores franceses imperecederos y auténticos en contra de la evolución perniciosa de la moderna sociedad industrial. Quizá, dado que así se afirma su superioridad y su utilidad social, la crítica a la modernidad económica y social que se promueve en estos estratos ha mostrado una continuidad notable. Como lo atestigua su cultivo de - esencialmente - los mismos motivos y temas hoy que hace cincuenta o incluso cien años, esta crítica continúa tiñendo sus convicciones y perspectivas sociales y políticas.

Tal crítica a la modernidad asciende a dos niveles temáticos distintos, aunque interrelacionados. En primer lugar, implica la denuncia de las manifestaciones concretas, físicas, de la modernidad, retratadas como un entorno hostil y opresivo en el cual el individuo se encuentra a sí mismo alienado. Inicialmente, la crítica está ligada a una deconstrucción

${ }^{30}$ Véase Gabriel Goodliffe, The resourgence of radical right in France: From boulangisme to the Front National, 2012, Nueva York, Cambridge University Press, pp. 39-40. 
negativa de la gran ciudad que, se considera, destila los efectos más deshumanizantes de la vida moderna sobre el individuo. En el entorno impersonal y alienante de la ciudad, la identidad del individuo se disuelve en una masa amorfa de individuos similarmente alienados. ${ }^{31}$ La comunicación con otros se vuelve imposible. La cultura moderna de trabajo y ocio, este último subtendido por la ubiquidad de la televisión, que entumece la mente, remplaza efectivamente la cultura de la conversación y la narrativa que sustentó las relaciones sociales en el pueblo. ${ }^{32}$ En este sentido, la aparición de la ciudad $-\mathrm{y}$ de la sociedad de masas que representa - marca el desgarramiento de los vínculos interpersonales cercanos que caracterizaron la vida social en los pueblos. Ello da lugar, entre los petits indépendants, a un anhelo nostálgico por un pasado rural en que la vida era más simple y más saludable y que, en contraste con la ciudad moderna, era sinónimo de su seguridad social y material.

Como corolario de esta interpretación negativa de la ciudad como metonimia de la sociedad industrial, los petits indépendants también lanzan invectivas en contra de las depredaciones del lugar de trabajo moderno. Retratado como el lugar de deshumanización individual y de alienación colectiva, el hombre queda reducido a ser un engrane en la "máquina" industrial, obligado a repetir día tras día y hora tras hora las mismas tareas embrutecedoras en un proceso de producción muy segmentado y compartimentado. Por virtud de su casi absoluta reorganización y mecanización, el lugar de trabajo industrial reproduce como microcosmos el entorno embrutecedor y la cadencia infernal de la ciudad moderna. Al mismo tiempo, el individuo está subordinado al funcionamiento primitivo de la máquina, principal representante de la producción en la fábrica. En cuanto tal, la crítica al lugar de trabajo industrial plasma un más amplio recelo ante el progreso tecnológico, celebrado por los campeones del industrialismo en particular y de la modernización en general. ${ }^{33}$

${ }^{31}$ Mayer, op. cit., p. 318.

${ }^{32}$ Ibid., p. 319.

${ }^{33}$ Esta crítica hace pensar en las sospechas expresadas por un artesano desde hace un siglo, justo a comienzos del siglo XX, acerca del potencial liberador de las nuevas máquinas y de la nueva tecnología. Véase Zdatny, op. cit., pp. 45-46 y Mayer, op. cit., pp. 477-478. 
Finalmente, los petits indépendants también culpan de la alienación del individuo a la plétora de los bienes de consumo que han inundado la sociedad francesa como resultado del progreso económico y de la innovación tecnológica en la moderna era industrial. La estandarización de los bienes debido a la mecanización y la reorganización de la producción se convierte en una uniformidad embrutecedora de consumo, que degrada inevitablemente el gusto personal y la individualidad. Las personas se vuelven cada vez más indistinguible unas de otras, dado que consumen los mismos bienes en cantidades siempre mayores. ${ }^{34}$ Asimismo, los nuevos materiales usados en la producción industrial son considerados como anuncio del triunfo de lo "químico", lo "sintético" y lo "artificial” sobre lo "natural”, lo "orgánico" y lo "auténtico". Mayer escribe: "Ante las verduras congeladas, ante la carne envuelta en celofán en el supermercado, [los petits indépendants] oponen, por comparación, la miel de la granja, el vino de la región, las cabezas de lechuga incrustadas en la tierra. Enfrentan un letanía completa de imágenes estereotípicas del campo, verde, fresco, odorífero, vigorizante a lo incoloro, lo inodoro y la frialdad cadavérica del supermercado". ${ }^{35}$

En una segunda etapa, los petits indépendants refuerzan su crítica a las manifestaciones concretas y ecológicas de la modernidad industrial con una condena a la corrosión moral, que ven como sinónimo de aque1la. Tres aspectos de la vida moderna en particular son objeto de su ataque. En primer lugar, denuncian el ethos dominante del consumismo - y la búsqueda de satisfacción inmediata que delata - como una de las fuentes principales de degradación individual y colectiva de la moderna sociedad capitalista. Asimismo, condenan la primacía superlativa otorgada al dinero en la sociedad moderna, con base en que reduce la

${ }^{34}$ Tal como Philip Nord ha mostrado en su estudio sobre los comerciantes de París a finales del siglo XIX, esos sentimientos se extendieron entre los petits indépendants tan pronto como los productos estandarizados de consumo producidos en masa hicieron su aparición en los mercados franceses, en la década de 1860. Medio siglo después, durante el periodo entreguerras, el presidente de la federación de carniceros y futuro funcionario de Vichy, Georges Chaudieu, expresó una preocupación similar cuando equiparó la producción industrial y el consumo modernos con la "monotonía, el gusto estandarizado [...] y la falta de contacto humano". Véase Philip Nord, Paris shopkeepers and the politics of resentment, 1986, Princeton, Princeton University Press, pp. 282-285, y Zdatny, op. cit., p. 46.

${ }^{35}$ Mayer, op. cit., pp. 321-322. 
existencia individual a una búsqueda incesante de riqueza y consumo ostentoso. ${ }^{36}$ Como el consumismo y el materialismo van en contra de su ética de frugalidad y abnegación, los petits indépendants los consideran intentos fútiles por compensar la vacuidad de la vida moderna. ${ }^{37}$

De igual modo, la búsqueda de la facilidad y la renuncia al esfuerzo, implícita en el materialismo y el consumismo de la sociedad moderna, está en contra de los ideales del trabajo duro y la abnegación que sustentan la visión del mundo de los petits indépendants. ${ }^{38}$ Dado que la gente renuncia al esfuerzo a cambio de placeres sencillos, la calidad del trabajo y de la producción se deteriora inevitablemente y contribuye a una condición general de desidia en la sociedad contemporánea. ${ }^{39}$ En cambio, los petits indépendants se ven a sí mismos como los últimos guardianes de las virtudes del esfuerzo, del trabajo duro y de la calidad, universalmente incumplidas en la sociedad moderna, lo que acentúa el conflicto insoluble entre su moralidad tradicional y los valores y procesos centrales de la avanzada sociedad capitalista.

Finalmente, esta denuncia de la búsqueda de satisfactores que tiene como resultado el abandono de los valores del trabajo duro y la abnegación, se amplía a una condena general al relajamiento de las costumbres, evidente en la sociedad francesa contemporánea. En esta crítica es central la condena al incremento del comportamiento licencioso e inmoral que presuntamente ha sido provocado por la modernidad socioeconómica. Una vez más, la ciudad moderna es objeto de especial crítica como semillero de inmoralidad, que se inició con la migración rural durante el último cuarto de siglo XIX. Observadores de la sociedad en la época de entreguerras afirmaban que la ciudad debía ser condenada no solo como un deshumanizante entorno físico y laboral, sino como

${ }^{36}$ Ibid., p. 328.

${ }^{37}$ De ahí las frecuentes alusiones por parte de los petits indépendants, entrevistados por Mayer, a la admonición cristiana, tomada del Evangelio, de que el hombre no puede vivir solo de pan y de que la riqueza en sí misma no aporta la felicidad. En palabras de un propietario de una tienda de quesos y lácteos. Ibid., p. 329.

${ }^{38}$ En particular, los petits indépendants deploran la habituación de los jóvenes a una vida fácil de comodidades y ocio, sinónimo, ante los ojos de muchos, de su búsqueda de una educación universitaria y la consecuente adopción de un desahogado estilo de vida estudiantil, desprovisto de rigor y disciplina. Ibid., p. 330.

${ }^{39}$ Ibid., p. 332. 
sede de "cines, salones de baile, y otras madrigueras de gérmenes y distracciones" que ejercían una "influencia nociva" en las costumbres de la nación. ${ }^{40}$

Tales sentimientos no están reducidos de ningún modo a la época de preguerra. Se puede descifrar una vehemencia equivalente en las denuncias hechas por los petits indépendants contemporáneos en contra de la laxitud moral de la cultura popular del presente. En esta moralización rigorista es central la denuncia de las holgadas costumbres sexuales identificadas con la cultura urbana y juvenil de hoy. Como eco de las quejas de entreguerras sobre la corrupción moral de las jóvenes del campo tras su llegada a la ciudad, los petits indépendants contemporáneos deploran los "estragos de la pornografía", expresan su indignación ante el hecho de que la gente (joven) "tiene sexo con varias parejas al mismo tiempo" y están indignados de que chicas de apenas catorce años tomen pastillas anticonceptivas para poder "acostarse con cualquiera" ${ }^{41}$ En cambio, los petits indépendants contemporáneos se retratan a sí mismos como guardianes del decoro sexual, que hacen gala “del respeto, del instinto para contenerse a sí mismos" y canalizan sus impulsos hacia el "deseo de construir un hogar". ${ }^{42}$ Se presentan como los últimos defensores de una moralidad tradicionalista diametralmente opuesta a la permisividad social y a la libertad cultural característica de la avanzada sociedad capitalista.

Su condena a la modernidad social y cultural conduce a los petits indépendants a imaginar la vuelta a un pasado más feliz en el cual no existen los aspectos socialmente deshumanizantes y moralmente corrosivos de la modernidad contemporánea. Se convierte en su propio mito de una época dorada constituida en torno a atributos estructurales y morales opuestos a los que identifican con la modernidad socioeconómica. En primer lugar, el entorno y los procesos censurados en la crítica a la modernidad urbana e industrial hallan su antídoto en las formas y los hábitos asociados con la interpretación mitificada de una sociedad precapitalista y específicamente rural. En contraste con el entorno

${ }^{40}$ Zdatny, op. cit., p. 45.

${ }^{41}$ Mayer, op. cit., p. 330.

${ }^{42}$ Loc. cit. 
infernal de la ciudad, los petits indépendants imaginan la vuelta a una concepción idealizada de la vida rural como fundamento para reconstruir la sociedad francesa. Evocando afectuosamente la belleza de sus paisajes y la frescura de su aire, retratan el campo como un escenario físico ideal para vivir, en comparación con el frío y contaminado confín de la ciudad.

Este escenario natural idealizado se vuelve una metonimia de la superioridad espiritual y normativa de la vida del campo para los petits indépendants. Extendidas las condiciones deshumanizantes del trabajo industrial y la anonimidad generalizada de la vida de la ciudad, la gente del campo se considera guía de una existencia mucho más gratificante, personal y colectivamente, que la de sus homólogos urbanos. Ofrece un ideal social al que siguen aspirando los petits indépendants, basado en restablecer los fuertes vínculos interpersonales característicos del pequeño pueblo de campo. ${ }^{43}$ Asimismo, en contraste con el entorno deshumanizante y el carácter embrutecedor del trabajo industrial, los petits indépendants defienden las virtudes de la creatividad y la individualidad inherentes a la destreza artesanal, en sí misma una regresión a un tiempo anterior, más simple, cuando Francia era un país rural. ${ }^{44} \mathrm{Tal}$ como vimos, el métier encapsula los valores de la creatividad, la habilidad y la individualidad humanas que sustentan la imagen económica y la identidad social del artesano y, en menor grado, del comerciante. En contraste con la plétora de los bienes estandarizados que salen de la línea de producción industrial y acaban en las estanterías de los supermercados, los petits indépendants aspiran a producir bienes de alta calidad,

${ }^{43}$ Los petits indépendants adoptaron varias estrategias con el fin de reproducir la atmósfera física y social de la vida pueblerina. Algunos buscaron restablecerse en las afueras, donde los árboles y la posibilidad de tener un jardín les recuerda el campo. Otros, al no poder volver jamás a su terruño, eligieron vacacionar ahí (una estrategia que, incidentalmente, también es característica de los obreros industriales de reciente origen rural). Finalmente, los petits indépendants trataron de recrear la atmósfera de su terruño dentro de los confines grises del quartier ("barrio") adecentando sus propias tiendas, irguiéndose a sí mismos como los conservadores, por medio de la relación cercana que mantienen con sus clientes, de las relaciones sociales estrechas que caracterizan a la vida del campo. Ibid., pp. 319-320. Acerca de las estrategias contemporáneas adoptadas por antiguos emigrantes rurales para recuperar la realidad física y la atmósfera social de la vida en el campo, véase Nicole Eizner y Bertrand Hervieu, Anciens paysans nouveaux ouvriers, 1979, París, L'Harmattan, pp. 118-119.

${ }^{44}$ Ibid., p. 322. 
productos naturales conectados con el entorno del campo, en lugar de piezas artificiales cuya autenticidad y frescura están degradadas fundamentalmente. ${ }^{45}$ Por tanto, al igual que imaginan el campo como antítesis de la ciudad, como entorno ideal en el cual vivir y trabajar, contrastan los bienes artesanales con los productos estandarizados en serie de la industria moderna, antítesis de los verdaderos valores de la producción francesa. Así, proyectan los valores de un orden pretérito, rural y precapitalista, cuya nostalgia los inspira a resistir la usurpación de la modernidad económica y social.

No es de extrañar que, como antídoto de las depredaciones morales de la época moderna, los petits indépendants oponen su propia moralidad tradicionalista construida en torno a los valores familiares y los principios del trabajo duro, la frugalidad y la abnegación. Continúan idealizando al pequeño productor propietario que fue predominante durante la belle époque y el periodo de entreguerras, y que se proyecta como columna vertebral de la moral y héroe espiritual de la sociedad francesa en la literatura de la época. ${ }^{46}$ Asimismo, la añoranza de los petits indépendants por la vuelta a estos valores tradicionales se confunde fácilmente con la nostalgia por las instituciones sociales que históricamente los hicieron valer. En particular, los petits indépendants contemporáneos llaman unánimemente a la restitución de la ley y el orden, clamando por una época en que el respeto a la ley era normal y generalizado, a diferencia del presente anárquico en que en que se incumple licenciosamente. ${ }^{47}$

Este llamado a un respeto mayor por la ley está acompañado por una disposición cada vez mayor, , a la represión. La tendencia se observa en diferentes ámbitos y excede (en algunos casos substancialmente)

${ }^{45}$ Este sentimiento resonó en un zapatero parisino quien, en defensa de su compañero petit commerçant, le exaltó a Mayer la frescura de la carne a la venta en la carnicería local, mientras que condenaba lo insípido del equivalente en el supermercado. Loc. cit.

${ }^{46}$ Como testimonio de la resistencia de este tropo, comerciantes y artesanos contemporáneos se identifican hoy con la imagen del "artesano como independiente, trabajador esforzado y desdeñoso del materialismo de la cultura urbana, industrial", como cuando la glorificación literaria de los pequeños productores y comerciantes alcanzó su cenit durante las décadas de 1920 y 1930 . Véase Zdatny, op. cit., p. 45.

${ }^{47}$ Mayer, op. cit., pp. 333-334. 
las tendencias represivas de la población general. ${ }^{48}$ En consecuencia, los petits indépendants expresan el grado más alto de confianza en los sistemas legales y de justicia entre los grupos socio-profesionales y confían más en la policía, el ejército y la gendarmería. No es sorprendente que entre este grupo social el sistema de justicia se vea como demasiado laxo. ${ }^{49}$ Además de expresar un deseo intenso de restituir la ley y el orden, los petits indépendants también prefieren aplicar las políticas más represivas con el fin de afirmar el respeto a la ley. Así, en 1979, 73\% de los petits indépendants (en comparación con el 53\% de los franceses en conjunto) consideraron que los veredictos dictados por los tribunales criminales franceses fueron demasiado indulgentes, y 77\% (con el 59\% entre la población general) pensaron que había sido un error conceder permisos a los reclusos. Finalmente, $75 \%$ de los petits indépendants (el $56 \%$ de la población general) se declararon a favor de la pena de muerte. ${ }^{50}$

El deseo de muchos petits indépendants de restituir los preceptos morales tradicionales en el centro de la vida social y personal estuvo acompañado frecuentemente por la reafirmación de la Iglesia como la representante principal de los valores tradicionales del país. Efectivamente, muchos deploraron el estado de la Iglesia contemporánea en Francia, sosteniendo que se había vuelto demasiado liberal y "laxa" como para ser un resguardo eficaz de las costumbres y los principios tradicionales. Por consiguiente, varios petits indépendants - particularmente mayores - rememoraban nostálgicamente a "sus antiguos sacerdotes", y algunos llegaron incluso a clamar por la restitución de la facción más tradicional de la Iglesia en Francia, considerada como la

${ }^{48}$ Por consiguiente, $52 \%$ de los petits indépendants encuestados en 1981 se declararon del lado de los "partidarios de la autoridad y de la disciplina más estrictas", frente a 46\% del público francés en conjunto. En asuntos específicos, sus sesgos represivos se expresaron en su creencia abrumadora ( $72 \%$ frente a $60 \%$ de los franceses en conjunto en 1978), de que la función de la educación era inculcar "los valores de disciplina y el esfuerzo", en lugar de "capacitar a la gente para tener una mente inquisitiva y crítica" (24\% frente a $35 \%)$. Asimismo, $32 \%$ de los petits indépendants (con 19\% de los franceses en conjunto en 1981) estuvieron en absoluto acuerdo con la declaración de que "no se puede criar a los hijos sin darles una buena tunda de vez en cuando". Ibid., pp. 498-499.

${ }^{49}$ Ibid., p. 385.

${ }^{50}$ Ibid., pp. 498-501. 
única encarnación organizacional de la fe católica capaz de defender los valores tradicionales. Este atractivo del catolicismo tradicionalista para un segmento significativo de los petits indépendants reflejó no tanto las preocupaciones doctrinales sobre la evolución de la Iglesia, sino más bien la convicción de que esa forma de catolicismo satisfizo mejor su vocación como instrumento de control social y fuente de autoridad moral. En este caso, como en otros, los petits indépendants estaban, como conjeturó Mayer, "inclinados instintivamente hacia la tradición y en contra del progreso". 51

A grandes rasgos, pues, el sentimiento general de misoneísmo representado por los petits indépendants franceses plasmó una aversión fundamental a las manifestaciones de la modernidad económica y social, y a la concomitante transformación de los valores. Recordar un pasado rural en que el pequeño propietario reinaba supremo y los valores tradicionales regían el comportamiento de la gente fue el principal corolario práctico del sistema cultural de la indépendance formulado por comerciantes y artesanos en Francia. Desde un punto de vista afectivo o psicológico, tal misoneísmo los proveyó de un mecanismo de defensa en contra de su cada vez más precaria posición socioeconómica dentro de la sociedad industrial. Como este misoneísmo legitima el papel socioeconómico de los petits indépendants en la sociedad capitalista avanzada, no debería sorprender que hallase su expresión más extrema en los momentos en que su papel y estatus estaban más amenazados.

Inevitablemente, el misoneísmo derivado del sistema cultural de la indépendance condiciona el comportamiento económico y político de los comerciantes y artesanos de varias maneras. En lo tocante a la esfera económica, el recelo mostrado por estos estratos ante el lugar de trabajo contemporáneo está impregnado por una mentalidad económica precapitalista radicalmente contraria a los imperativos de racionalidad y eficiencia que determinan las formas más avanzadas de producción industrial. Tal como vimos, esta mentalidad está marcada por el apego que sienten los petits indépendants por su oficio, que conciben como una vocación determinante para la vida, así como por el apego a su familia, reclutada para el servicio de su empresa. Esto necesariamente da

${ }^{51}$ Ibid., pp. 333 y $507-508$. 
lugar a un criterio afectivo de hacer negocios que es incompatible con los preceptos racionalistas de ganancia y maximización de la cotización de los que depende la toma de decisiones en la avanzada empresa capitalista. ${ }^{52}$ De ahí la adopción por parte de los petits indépendants de lo que un observador ha denominado un "acercamiento no económico a la economía". 53

En cuanto tal, la mentalidad económica tradicional desarrollada por los petits indépendants es diametralmente opuesta a la del empresario capitalista "moderno". En primer lugar, mientras que este busca mejorar el rendimiento económico de su negocio, aquel lo considera primeramente y ante todo como un vehículo para ejercer su oficio. Por consiguiente, mientras que el empresario se propone expandir su negocio, agrandar su cuota de mercado y maximizar su ganancia, el indépendant busca simplemente generar suficientes ingresos para ser capaz de ejercer su oficio y hacerse cargo de las necesidades de su familia. En esencia, el petit indépendant lucha por maximizar la libertad para continuar con su métier y maneja su empresa como le parece adecuado. Prefiere preservar su independencia a la posibilidad de acrecentar su empresa, si esto ha de significar renunciar al control o aceptar una injerencia externa. ${ }^{54}$ En este sentido, la mentalidad económica de los petits indépendants es explícitamente malthusiana (en el sentido francés del término) y está sintetizada en la consigna: "es mejor ser un pequeño patron que un gran lacayo". Al rechazar el crecimiento en aras de la estabilidad y la posibilidad de mayores ganancias a cambio del control independiente, los petits patrons franceses condenan a sus empresas a permanecer pequeñas. Es esta perspectiva la que contribuyó a la profusión de empresas pequeñas e ineficientes que estorban a las estructuras industriales y comerciales del país hasta el día de hoy.

${ }^{52}$ En un pasaje cuyo punto principal podría aplicarse igualmente bien tanto a los pequeños comerciantes como a los artesanos, Bernard Zarca ha subrayado diestramente la vacuidad analítica ligada al intento de entender el comportamiento económico de los petits indépendants según los esquemas abstrusos y absolutistas de la racionalidad económica que dominan hoy gran parte de la teoría y pasan por alto los importantes factores psicológicos, culturales e históricos que inevitablemente se entremezclan y delatan su comportamiento económico. Zarca, op. cit., p. 138.

${ }^{53}$ Mayer, op. cit., p. 377.

${ }^{54}$ Gresle, "L'indépendance professionnelle: Actualité et portée du concept dans le cas français", p. 484 y Zarca, op. cit., p. 147. 
Semejante aproximación malthusiana a los negocios implica que los principios administrativos y las prácticas comerciales de la pequeña empresa independiente se estructuran alrededor del hábito y la costumbre, en lugar de la racionalidad característica del moderno empresario capitalista. La empresa es concebida como un instrumento de producción antes que como una inversión de capital y el petit patron la maneja como una inmediata actividad "económico-sustentante", antes que como un medio de capitalizar su inversión a largo plazo..$^{55}$ Esta aproximación visceral e inmediata al manejo de la empresa lleva a los petits indépendants a adoptar una perspectiva de negocios muy conservadora que es fundamentalmente incompatible con el afán de correr riesgos que define al empresario moderno schumpeteriano. Sus principios de negocios se resumen mejor con la admonición de "vender poco, pero caro, lo que ya se tiene", emplear el menor personal posible y calcular tan "mezquinamente" como sea posible. Bajo esta luz, el petit indépendant es "el hombre de pocos ahorros y pocas ganancias". ${ }^{56} \mathrm{Y}$ cuando genera ganancias, raramente las canaliza a su empresa, sino que invierte en activos tradicionalmente seguros, de bajo rendimiento, como bienes raíces o, históricamente al menos, bonos del tesoro respaldados por el gobierno. En esencia, pues, el petit indépendant común adoptó estrategias económicas defensivas tanto para manejar su negocio como para invertir, las cuales recuerdan a los petits rentiers ("pequeños rentistas") de antaño. Como antítesis cultural del empresario schumpeteriano, "todas sus elecciones delatan — como observa Mayer — la búsqueda de seguridad [y] el temor a los riesgos". ${ }^{57}$

${ }^{55} \mathrm{La}$ falta en la mentalidad del petit indépendant de un enfoque de largo plazo encaminado a hacer dinero, subordinada al cálculo económico racional implícito en invertir en el propio negocio y expandirlo, se convirtió en una relación concreta e inmediata con el dinero. Tras ganarlo, "o era gastado o hecho a un lado". Más que ver sus recaudaciones como medios para maximizar su utilidad futura y su potencial de ingresos, los petits indépendants las concibieron como "efectivo a la mano" palpable e inmediato, en lugar de ganancias potenciales que pudiesen ser reinvertidas en sus negocios. Tal como señala Mayer, una aproximación tan burda reflejaba una carencia básica de capacitación en los negocios, lo que delata la ignorancia de los petits indépendants sobre las prácticas de negocios más elementales, como la contabilidad básica, el seguimiento de ventas en relación con el inventario, etc. Mayer, op. cit., pp. 365, 374-377 y 380 ss.

${ }^{56}$ Mayer, op. cit., p. 367.

${ }^{57}$ Ibid., p. 368. La negativa a invertir en los mercados financieros se expresa desde hace tiempo en la distinción que hacen los petits indépendants entre las ganancias económicas 
El rechazo a los riesgos característico de los petits indépendants se convirtió en un repudio más amplio al principio de competencia. Muchos pequeños productores y comerciantes sostienen que la competencia es inmoral e injusta, particularmente cuando enfrenta a las pequeñas empresas con las grandes. De ahí el postulado de los petits indépendants de que "cada pequeño negocio tiene 'el derecho a vivir' y 'cada persona debe ser capaz de ejercer su oficio"". ${ }^{58}$ Particularmente, en contraste con los defensores del libre mercado irrestricto, los petits indépendants presentan el concepto de "competencia leal": la creencia de que la competencia solo está justificada si enfrenta a adversarios de igual tamaño en un "campo de juego nivelado". ${ }^{59}$ Puesto que las cadenas de supermercados y las grandes empresas industriales no solo son más grandes que las pequeñas empresas administradas por los petits indépendants, sino que también, sostienen estos, gozan de ventajas fiscales injustificables y protecciones políticas del Estado, no debería ser posible, pues es injusto, que compitan en contra de las pequeñas empresas autónomas. La noción de "competencia leal" es la principal justificación moral que legitima la entrada de los petits indépendants en alianzas sectoriales para enfrentar a los supermercados y otros grandes minoristas. ${ }^{60}$ Esta iniciativa acaba convertida en un ethos proteccionista que está irreduciblemente en desacuerdo con los principios de libre comercio defendidos por los economistas liberales clásicos y por los defensores del capitalismo de mercado sin restricciones. Así, esta noción constituye todavía otro refuerzo de la mentalidad precapitalista o, incluso, anticapitalista de los petits indépendants. En resumen, esta mentalidad es

\footnotetext{
"legítimas", adquiridas mediante el trabajo duro y la economía, y las "ilegítimas", adquiridas por especulación. Como recuerda Jacques Capdevielle, hasta el periodo entreguerras — que vio lo que él llama la "democratización" de los mercados financieros - no hubo una evolución de los petits indépendants hacia la consideración de la inversión especulativa como un medio aceptable de hacer dinero. Jacques Capdevielle, Le fétichisme du patrimoine, 1986, París, Presses de la Fondation National de Sciences Politiques, pp. 230-234 y 210-211.

${ }^{58}$ Mayer, op. cit., p. 369.

${ }^{59}$ Loc. cit.

${ }^{60}$ En la práctica, el afianzamiento de la unidad petit indépendant ante la competencia injusta aminoró la competencia entre ellos dentro del quartier. Comerciantes y artesanos pactaron ententes informales, lo que tuvo el efecto de impedir que la competencia - incluso la de clase "leal"- - se volviese demasiado fuerte entre ellos. Ibid., p. 370.
} 
un componente fundamental de la "lucha en retaguardia" que libran en contra de las fuerzas de la modernidad socioeconómica. Al igual que sus ideas misoneístas, les sirve para legitimar la resistencia de pequeños artesanos y comerciantes a las estructuras y procesos del capitalismo moderno, y ofrecer una justificación esencialmente moral para su supervivencia en la sociedad industrial.

En una segunda etapa, el modelo cultural de la indépendance también conduce a los comerciantes y artesanos a desarrollar ciertas disposiciones políticas. En primer lugar, el total ensimismamiento en sus ocupaciones significa una ignorancia general de los asuntos políticos, lo cual lleva a los petits indépendants a ver la política como el dominio exclusivo de políticos y partidos, de los que están muy alejados. Al mismo tiempo, su experiencia individualista del trabajo les impide establecer las identificaciones y las vinculaciones colectivas que requiere la acción política continua. Como escribió François Gresle, "al creer que cumple un destino singular en relación con sus pares y con la sociedad, el indépendant tiene dificultades para trascender el egocentrismo fundamental al que llega inevitablemente por el reduccionismo de su gremio". ${ }^{61}$ Así, Gresle demuestra (al menos para periodos de relativa estabilidad económica y social) lo que otro autor ha denominado un "rechazo a la política", la negativa a comprometerse cotidianamente con los procesos y los asuntos políticos. ${ }^{62}$

El rechazo a la política se articula en torno a ciertos temas básicos. Primero, plasma el recelo fundamental de los petits indépendants del Estado y sus representantes, una proclividad expresada con mayor obviedad en su constante oposición a la intervención estatal en la esfera económica. Esta oposición a la intervención estatal los lleva a criticar las dos encarnaciones principales del Estado moderno francés: el Estado

${ }^{61}$ Arno Mayer formula este punto de manera un tanto diferente, sosteniendo que las clases medias bajas tradicionales solo exhibieron un sentido de identidad o consciencia de clase en tiempos de crisis política y económica, cuando sintieron que sus intereses económicos estaban amenazados. Por el contrario, en periodos de relativa calma solo expresaron un difuso sentido de concientización de clase, insuficiente para constituir los fundamentos de un programa o proyecto político común. Al respecto, véase Arno Mayer, "The lower middle class as historical problem", The Journal of Modern History, 47/3 (1975), p. 434.

${ }^{62}$ Mayer, op. cit., pp. 392-393. 
de bienestar (l'État providence) y el Estado burocrático (l'État fonctionnaire). El estado de bienestar es culpable, para ellos, de acabar con la iniciativa personal y educar generaciones de indolentes beneficiarios de la ayuda estatal, que preferirían permanecer desempleados y continuar recibiendo beneficios en lugar de encontrar un trabajo. ${ }^{63}$ Del mismo modo, los petits indépendants también dirigen su ira en contra de la burocracia estatal, un representante, ante sus ojos, del derroche y la desidia, cuyos agentes - los odiados fonctionnaires - consideran tan holgazanes como incompetentes. ${ }^{64}$ En suma, el Estado burocrático de bienestar es visto por los petits indépendants como una fuente ineficiente de parálisis económica y social, cuyas funciones estarían mejor en la iniciativa privada. En el mismo tenor, también se oponen al Estado moderno con base en que ellos están desproporcionadamente gravados, pero se benefician menos de su asistencia. En este sentido, el liberalismo económico profesado por este grupo toma más frecuentemente la forma de una denuncia de las intrusiones — sean fiscales o de otro tipo- del Estado en su vida. Básicamente, en este sentido negativo, mediante su rechazo de la intervención del gobierno, puede decirse que los petits indépendants son económicamente "liberales".

Este liberalismo "defensivo" y el rechazo a la intervención gubernamental se convierte, políticamente, en un rechazo a las ideologías del socialismo y el comunismo, que no solo les parecen sinónimos de desorden revolucionario, sino que discrepan, en un nivel más fundamental, con el requisito de la propiedad económica individual que es la condición esencial de la indépendance. Desde su perspectiva, la única forma verdadera de libertad reside en la ética del trabajo y las posibilidades de avance social que ofrece — que, al trabajar duro, los asalariados industriales o los employés ("empleados") del sector de servicio pudiesen aspirar algún día a "montar un negocio" como ellos lo hicieron. En este sentido, los petits indépendants rechazan el principio de igualdad social que defienden el socialismo y el comunismo y, en su lugar, ponen su fe en la meritocracia como fundamento para determinar los

${ }^{63}$ Ibid., p. 385.

${ }^{64}$ Ibid., p. 386. 
resultados económicos y sociales. ${ }^{65}$ Consideran que la desigualdad social tiene una justificación natural, que es el resultado lógico de las diferencias innatas de habilidades y talento que separan a los individuos. Por consiguiente, rechazan incondicionalmente las prescripciones niveladoras de los partidos izquierdistas y de los sindicatos, diciendo que entorpecen la libertad de iniciativa y de empresa celebradas por el petit patron. ${ }^{66}$

Con todo, la noción de competencia "leal" — es decir, restringidadefendida por los petits indépendants disminuye, en la práctica, la fuerza de su compromiso con el liberalismo económico, porque frecuentemente los conduce a adoptar prescripciones políticas y económicas incongruentes, cuando no contradictorias. El ejemplo más claro es su exigencia de que, pese a su crítica virulenta al Estado de bienestar, este les provea asistencia financiera y protección regulatoria frente a la competencia económica del comercio y de la industria a gran escala. ${ }^{67}$ Y cuando juzgan que el Estado no está haciendo suficiente a su favor, dirigen su ira en contra de la clase política en su conjunto, acusándola de mostrarse sorda a los apuros del esforzado trabajador francés que afirman representar. ${ }^{68}$ En suma, los petits indépendants se sienten cada vez más desconectados y cada vez menos representados por los líderes políticos de la nación, de modo que el patente fracaso de estos últimos al tratar de protegerlos se convierte en la perdurable desconfianza hacia los políticos de parte de los petits indépendants, que eventualmente se muestran favorables a movimientos y partidos opositores. ${ }^{69}$

De lo anterior se desprende que, como función de su mentalidad cultural, los petits indépendants franceses han adoptado una opinión pasiva

${ }^{65}$ Ibid., p. 418.

${ }^{66}$ Acerca del parecer del petit indépendant sobre los sindicatos y citas diversas, véase Mayer, op. cit., pp. 396-397.

${ }^{67}$ Las políticas estatales específicas para asistir a los petits indépendants incluirían, presumiblemente, fondos para mantener sus instalaciones, incentivos económicos y (más) exenciones fiscales a pequeños negocios, indemnizaciones para los petits patrons que quiebren. Es decir, precisamente las políticas que atacan con virulencia por motivos económicos liberales cuando benefician a los grandes intereses industriales y comerciales. Véase ibid., p. 390.

${ }^{68}$ Ibid., p. 388.

${ }^{69}$ Ibid., p. 394. 
y negativa de los procesos, las instituciones y las élites políticas. Efectivamente, esta orientación fundamental los ha inclinado de forma periódica hacia los movimientos de derecha radical. No dejan de sorprender las coincidencias entre el modelo cultural de la indépendance que sustenta la mentalidad de los petits indépendants y el discurso de la derecha radical. Ambos ponen el mismo énfasis en la familia como la unidad social fundamental, en el centro de sus respectivas cosmovisiones. Cada uno manifiesta el mismo apego a una concepción primordial "arqueoliberal" de la economía, basada en la santidad de la propiedad privada, la competencia leal y la limitada intervención estatal. ${ }^{70}$ Finalmente, cada uno postula una ética tradicionalista y una moralidad rigorista y adversa a la moderna sociedad industrial. Al proyectar la visión de un pasado mítico, glorificaron el campo francés y la vida rural como se refleja en su filosofía en torno al rusticismo. ${ }^{71}$ En suma, uno podría concluir que el modelo cultural que caracteriza a los petits indépendants y el discurso de la derecha radical se reflejaron mutuamente de diversos modos, una semejanza reforzada por su aparición a finales del siglo XIX y por su continua evolución entrecruzada.

En términos más generales, como resultado de la transformación arrolladora de la economía y de la sociedad francesas, los petits indépendants estuvieron sujetos cada vez más a las crisis de identidad - lo que el sociólogo francés Alain Bihr ha denominado una "crisis cultural"-, lo cual los hizo receptivos al discurso de la derecha radical. ${ }^{72}$ En una primera etapa, los nuevos métodos para organizar la producción, que implican la expansión cada vez mayor, la reorganización y la automatización del lugar de trabajo, sonaban como la sentencia de muerte para los antiguos valores del oficio o métier que sustentaron sus identidades profesionales y sociales. ${ }^{73}$ Estos nuevos modos de organizar la producción se basaron en los principios de la racionalidad económica que, por postular criterios puramente financieros de desempeño

\footnotetext{
${ }^{70} \mathrm{He}$ tomado prestado este término de Patrick Fridenson, "L'idéologie des grands constructeurs dans l'entre-deux-guerres", Le mouvement social, 81 (1972), p. 52.

${ }^{71}$ Zdatny, op. cit., p. 45

${ }^{72}$ Acerca de este punto, véase la nota 6, supra.

${ }^{73}$ Véase Gresle, Indépendants et petits patrons, pp. 190, 187, 190-191, 192.
} 
y rendimiento, fueron anatema para el maltusianismo económico de los petits indépendants.

La intervención de nuevas estructuras, prácticas y normas en la vida económica del país reflejaron cambios más amplios en el entorno cultural y social general que hizo sentir a los petits indépendants cada vez más incómodos en la moderna sociedad francesa. Su inquietud subrayó la incompatibilidad creciente entre su concepción de la sociedad fundada en el pequeño productor y el entorno moderno industrial cada vez más dominante, que anunciaba la disolución de los entornos familiares y reconfortantes del quartier del que fueron ejes económicos y sociales tradicionales. En este sentido, el impacto nocivo de la concentración comercial e industrial sobre los petits indépendants, ya sea del grand magasin ("gran almacén") de las décadas de 1880 y 1890 o el supermarché ("supermercado") y el hypermarché ("hipermercado") de las décadas de 1960 y 1970, debería medirse no solo por su deteriorada posición económica, sino también por la dislocación de los entornos y las relaciones sociales que moldearon su cosmovisión sociopolítica. ${ }^{74}$ En particular, la aparición de la industria y el comercio concentrados se consideró una amenaza a las dos instituciones sociales de mayor importancia para los petits indépendants: la república de los pequeños productores y la familia patriarcal tradicional. En primer lugar, puesto que ningún grupo dio la bienvenida a la República más fervientemente que los pequeños productores, su extinción progresiva como resultado de la concentración industrial y comercial fue interpretado como un peligro mortal para el orden republicano en su guisa primordial y auténtica. En segundo lugar, al arruinar pequeñas empresas, consideradas como corolario socioestructural de la familia tradicional, la gran fábrica y el grand magasin fueron vistos como un ataque a esta. En suma, la extinción progresiva del petit commerce y el artisanat, y la consiguiente delicuescencia del quartier, anunciaron una catástrofe política y normativa, indicativa de la muerte de una Francia sempiterna que se identificó con la visión pequeño-productora del morcellisme ("morcelismo" o socialismo liberal) y la perpetuación de los valores familiares tradicionales. ${ }^{75}$

\footnotetext{
${ }^{74}$ Véase Nord, op. cit., p. 266, y Mayer, op. cit., p. 320.

${ }^{75}$ Véase Nord, op. cit., p. 265, y Mayer, op. cit., capítulos 7 y 8, passim.
} 
Igualmente, los petits indépendants culparon a la sociedad industrial de acelerar la destrucción del entorno rural natural y de corromper las vías tradicionales de vida históricamente asociadas con él. ${ }^{76} \mathrm{El}$ despojo y vaciamiento del campo como resultado de la industrialización fue un símbolo del colapso moral general causado por la modernidad económica y social. Como vimos, para los petits indépendants la modernidad introdujo un relajamiento pernicioso de las costumbres, incluso su perversión, que fue evidente en el aumento pronunciado de las formas antisociales de comportamiento: la floreciente criminalidad, la prostitución y la pornografía, la aparición de una cultura joven hipersexuada y adicta a las drogas, la erosión de la ética de trabajo y la creación de un número cada vez más grande de assistés ("beneficiados") de políticas de bienestar que en realidad recompensaban la "pereza". Esta disolución moral se vio acompañada de una pérdida paulatina del respeto, sobre todo entre los jóvenes, a los códigos tradicionales de autoridad, en particular, la familia patriarcal y la Iglesia católica. ${ }^{77}$ En medio de esta degradación moral universal, los petits indépendants se vieron a sí mismos como el único baluarte para la defensa de los valores tradicionales. Como cultivan un sentido profundamente palpable de superioridad moral basado en su respeto a tales valores, se retrataron a sí mismos como el último bastión, del que dependía en última instancia la redención moral y el redressement ("enderezamiento") social del país. Este sentido general de inminente colapso moral y desintegración social estuvo acompañado, para muchos petits indépendants, por un sentimiento igualmente universal de degradación de las normas

${ }^{76}$ Estos sentimientos fueron más evidentes en la literatura "rusticista" que cobró importancia en la fin-de-siècle de Francia y experimentó un resurgimiento durante el periodo de entreguerras. En esta literatura, la ciudad, París en particular, aparecía proyectada como una madriguera de promiscuidad, enfermedad y depravación sexual. En su estudio sobre los comerciantes de París, Mayer encontró que esa misma perspectiva estaba generalizada entre los petits indépendants contemporáneos, que tendían a idealizar la vida de campo como contrapunto de las influencias inmorales y deshumanizantes de la moderna vida urbana. Acerca de estas imágenes y motivos diversos, véase Nord, op. cit., pp. 269-270, y Zdatny, op. cit., p. 45.

${ }^{77} \mathrm{La}$ importancia dada por los petits indépendants a la dislocación de los códigos tradicionales de autoridad familiar y religiosa, y la profunda preocupación que esto suscitó entre ellos, se manifiesta en las respuestas de muchos de los comerciantes parisinos que fueron entrevistados por Mayer para su estudio. Mayer, op. cit., pp. 331 y 333. 
culturales, sobre todo las estéticas. Semejante crítica vio, en los materiales y las formas impersonales que definieron el entorno urbano e industrial, símbolos elocuentes de la frialdad deshumanizante de la época moderna. En su modismo estético, los petits indépendants compararon los materiales "modernos", como el acero, el concreto y el vidrio, con los insumos tradicionales añejados, como la madera y la piedra, que han sido los objetos sempiternos de la destreza artesanal. ${ }^{78}$

Así, con cualquier parámetro, la reconfiguración de la economía y la sociedad francesas a lo largo de la época del desarrollo capitalista fue una experiencia traumática para los petits indépendants. Indujo un permanente estado de disonancia cognitiva entre ellos, resultado del antagonismo insoluble entre su visión pequeño-productora de la sociedad y la economía, y las estructuras y valores que acompañan la civilización industrial. En primer lugar, el avance de las relaciones económicas y sociales capitalistas sirvió para deslegitimar y desacreditar el ethos de la indépendance, sobre la cual basaron su identidad social. La singular ausencia de un nuevo ethos colectivo, mediante el cual pudiese tener sentido el orden social y pudiesen definir su lugar dentro de él, volvió cada vez más inhóspita e ininteligible para ellos la vida en la sociedad industrial moderna. Así, mientras la sociedad francesa sufrió una mutación acelerada, a los petits indépendants les pareció más y más difícil dar coherencia conceptual y afectiva a su experiencia de la modernidad. Como conjeturó un escritor, carecieron de un orden simbólico que fuera "capaz de proveer y unificar los puntos de referencia existenciales que dieron significado a sus vidas". ${ }^{79} \mathrm{De}$ ahí la "crisis de significado" sufrida por los miembros de estos grupos

${ }^{78}$ En suma, la dislocación ecológica, estética e incluso sensorial a la que los petits indépendants fueron sometidos, transformó la moderna configuración urbana en un entorno cada vez más hostil e irreconocible para ellos. Simbolizó su propio declive en una época cada vez más acelerada de innovación tecnológica y modernización económica. Véase Nord, op. cit., p. 278, y Mayer, op. cit., p. 317.

${ }^{79}$ Bihr, Le spectre de l'extrême droite: les français dans le miroir du Front National, p. 130. Acerca del concepto de disonancia cognitiva y su aplicación a las esferas sociales y políticas, véase Birgitta Orfali, L'adhésion au Front National. De la minorité active au mouvement social, 1990, París, Kimé, pp. 222-224. 
"antimodernos" dentro de la sociedad industrial avanzada, que ponían en duda su relación, su identidad y su papel en el mundo social. ${ }^{80}$

La incapacidad de los petits indépendants para encontrar un significado en la moderna sociedad industrial y la consiguiente búsqueda de nuevas formas de identidad los llevó a identificarse masivamente con la derecha radical en ciertas coyunturas de la historia francesa reciente. Las semejanzas temáticas y simbólicas entre esta ideología y el ethos de la indépendance, sin mencionar su capacidad de ofrecer cómodos chivos expiatorios para culparlos de los problemas, volvió a esta corriente de derecha una fuente ideal de consuelo e identificación para los petits indépendants.

Sin embargo, a pesar de estas semejanzas, es importante recalcar que no había nada inherente en el modelo cultural de la indépendance que automáticamente inclinase a los petits indépendants hacia la derecha radical. Dicho de otro modo, no fue por su mentalidad cultural de clase (con la que adoptaron su peculiar papel económico y su posición social) que los petits indépendants llegaron a constituir históricamente la fuente principal de apoyo para la derecha radical. Fue necesario que se desplegase mucha historia y que ocurriesen muchos sucesos políticos para que esto llegara a suceder. En efecto, fue esta mentalidad cultural, combinada con las cada vez más intrusivas políticas intervencionistas y bienesta-

${ }^{80}$ En este sentido, la crisis que aflige a los petits indépendants se extiende mucho más allá de los procesos estructurales objetivos y de los indicadores materiales concernientes a su función profesional o condición socioeconómica como grupo. Más bien, lo sienten, primeramente y ante todo, en un nivel afectivo, subjetivo, como una función de su experiencia culturalmente tensa y simbólicamente discordante con el mundo moderno. Esta crisis subjetiva del significado, vinculada con la pérdida de significación e identidad individuales dentro de la sociedad contemporánea, hace pensar en la "histéresis del habitus" descrita por Pierre Bourdieu, mediante la cual "los esquemas de percepción, de apreciación y de acción, que han sido internalizados por el individuo [...] como una función de su confrontación rutinaria con la realidad social", se vuelven cada vez más impracticables e irrelevantes por su contradicción insostenible con las "exigencias objetivas" del entorno socioestructural y sociocultural. De acuerdo con Bourdieu, tales situaciones de disyunción o conflicto entre las orientaciones subjetivas, que están ligadas en el habitus individual y las condiciones objetivas características del entorno externo, dan lugar a "una gama de comportamientos adaptativos" que oscilan entre la "simple resignación" y la "revuelta extrema". Citado en Michel Dobry, Sociologies des crises politiques. La dynamique des mobilisations multisectorielles, 1986, París, Presses de la Fondation Nationale des Sciences Politiques, pp. 241 y 243. 
ristas perseguidas por un Estado republicano antes protector y solícito con el fin de racionalizar la estructura económica del país e integrar a las masas asalariadas dentro del sistema democrático desde el final de la Segunda Guerra Mundial, lo que progresivamente puso a los petits indépendants en su contra y los dispuso favorablemente hacia la política y las posturas opositoras y de asedio de la derecha radical.

En este sentido, podría decirse que el sistema cultural de la indépendance hizo poco para proteger a los comerciantes y artesanos del discurso y el programa de la derecha radical. Solo junto con las experiencias y los recuerdos políticos acumulados de los petits indépendants, y únicamente en las condiciones de las crisis sociales y culturales esbozadas aquí, esta mentalidad cultural habría ayudado a inclinarlos hacia esa corriente. 
Se prohíbe su reproducción total o parcial por cualquier medio, incluido electrónico, sin permiso previo y por escrito de los editores. 